CLINICAL STUDY

\title{
Short-term topiramate treatment does not improve insulin sensitivity or secretion in obese insulin-resistant women
}

\author{
Maria A Sleddering ${ }^{1, *}$, Marieke Snel ${ }^{1, *}$, Trea C M Streefland ${ }^{2}$, Hanno Pijl ${ }^{2}$ and Ingrid M Jazet $^{1}$ \\ Departments of ${ }^{1}$ General Internal Medicine (C4-R) and ${ }^{2}$ Endocrinology and Metabolism, Leiden University Medical Center, PO Box 9600 , \\ 2300 RC Leiden, The Netherlands \\ (Correspondence should be addressed to M A Sleddering; Email: m.a.sleddering@lumc.nl)
}

*(M A Sleddering and M Snel contributed equally to this work)

\begin{abstract}
Objective: Long-term treatment with topiramate reduces body weight and improves insulin sensitivity in obese humans. Our aim was to evaluate the effect of topiramate treatment for 4 weeks on insulin sensitivity and secretion, independent of weight loss.

Design: Randomized, double-blind, crossover, placebo-controlled study.

Methods: Thirteen obese (BMI $36.6 \pm 1.3 \mathrm{~kg} / \mathrm{m}^{2}$ (mean \pm s.e.m.)), insulin-resistant (homeostasis model of assessment-insulin resistance $2.0 \pm 0.2$ ) women received topiramate ( $\mathrm{T}$, maximum dose of $75 \mathrm{mg}$ ) and placebo $(\mathrm{P})$ for 4 weeks, separated by a 4 -week washout period. Insulin sensitivity and $\beta$-cell function were assessed using a two-step hyperinsulinemic euglycemic clamp with stable isotopes and a hyperglycemic clamp.

Results: Hepatic and peripheral insulin sensitivities were not affected by topiramate treatment (glucose disposal rate (step 1 (insulin infusion rate $10 \mathrm{mU} / \mathrm{m}^{2}$ per $\mathrm{min}$ ) T: $17.5 \pm 0.8$ vs P: $18.5 \pm 1.0 \mu \mathrm{mol} / \mathrm{kg}_{\mathrm{LBM}}$ per $\min , t=1.016, P=0.33$; step 2 (insulin infusion rate $40 \mathrm{mU} / \mathrm{m}^{2}$ per min) T: $27.9 \pm 3.2 \mathrm{vs}$ P: $28.8 \pm 1.9 \mu \mathrm{mol} / \mathrm{kg}_{\mathrm{LBM}}$ per min, $\left.t=0.418, P=0.68\right)$ ). Subjects lost a small amount of weight during the topiramate period ( $\mathrm{T}:-1.0 \pm 0.2 \mathrm{vs} \mathrm{P}:-0.1 \pm 0.2 \mathrm{~kg}, t=2842, P=0.15$ ). There were no changes in body fat mass, blood pressure, and fasting glucose. $\beta$-Cell function was not affected by topiramate as evidenced by an unaltered area under the curve of early (0-10 min; T: $1929.6 \pm 265.7$ vs P: $2024.7 \pm 333.6 \mathrm{pmol} / \mathrm{l}, t=-0.357, P=0.73)$ and late $(80-120 \mathrm{~min}$; T: $28017.7 \pm 5029.9$ vs P: $31567.7 \pm 5376.2 \mathrm{pmol} / \mathrm{l}, t=-1.481, P=0.16)$ phase insulin levels during hyperglycemia. The use of topiramate was associated with significant side effects such as paresthesia, nausea, dizziness, and concentration problems.

Conclusions: Low-dose topiramate treatment for 4 weeks, relative to placebo, had no significant effect on insulin sensitivity in overweight/obese adult females without established diabetes.
\end{abstract}

European Journal of Endocrinology 167 839-845

\section{Introduction}

Topiramate is a broad-spectrum neurotherapeutic agent approved for selected seizure disorders and migraine prophylaxis. A potential beneficial side effect is the dosedependent reduction in body weight, which was verified in healthy obese subjects $(1,2,3,4)$. Moreover, animal studies show that topiramate has an insulin-sensitizing effect and improves obesity-associated $\beta$-cell dysfunction in rats, independently of any reduction in food intake and weight loss $(5,6,7,8)$. In obese type 2 diabetes (T2DM) patients, long-term topiramate treatment led to a decrease in weight, HbAlc, and 2-h plasma glucose level in response to an oral glucose tolerance test (OGTT) $(9,10,11)$. Whether these (insulin-sensitizing) effects on glucose metabolism in humans are independent of its impact on body weight is, however, unknown.
The aim of this study was to evaluate the effect of topiramate treatment independent of weight loss in obese insulin-resistant women. To this end, we conducted a study with short-term, low-dose topiramate treatment. Outcome parameters were insulin sensitivity and insulin secretion, measured using a two-step hyperinsulinemic euglycemic clamp with stable isotopes and a hyperglycemic clamp.

\section{Materials and methods}

\section{Subjects}

Female subjects aged 18-70 years, with a BMI between 27 and $44 \mathrm{~kg} / \mathrm{m}^{2}$ and a homeostasis model of assessment-insulin resistance (HOMA-IR) above 1.7, were eligible for enrollment in the study. Subjects were 
recruited via advertisements in local newspapers. Exclusion criteria were smoking, recent weight change ( $>3 \mathrm{~kg}$ within the last 3 months), psychiatric disorders or use of antipsychotic/antidepressant drugs, any significant chronic disease (including T2DM), use of medication known to influence glucose metabolism, and difficulties to insert an intravenous catheter. Premenopausal subjects were required to use an approved method of birth control.

This study was conducted in accordance with the Declaration of Helsinki (12) and approved by the local ethics committee. Informed consent was obtained from all subjects. The study was registered under NTR1286 (www.trialregister.nl).

\section{Study design}

Subjects were enrolled in a randomized, double-blind, placebo-controlled, cross-over intervention study with a 4-week washout period between the two interventions $(\mathrm{T} 1 / 2$ of topiramate $=21 \mathrm{~h})$. Subjects were randomly assigned to topiramate (to a maximum of $75 \mathrm{mg} /$ day) or placebo as the first intervention, using a standardized randomization list as prepared by a statistician. The study was strictly double blind; subjects as well as study staff were unaware of the order of treatment throughout the whole study period. To minimize side effects, subjects received the following titration schedule for the topiramate treatment: week 1, $25 \mathrm{mg}$ topiramate once daily; week 2, $25 \mathrm{mg}$ twice daily; and weeks 3 and $4,25 \mathrm{mg}$ in the morning and $50 \mathrm{mg}$ in the evening. During both intervention periods, subjects visited the research center weekly for anthropometric measurements, laboratory tests, and a tablet count for compliance registration. Adverse events were recorded by the research physician by systematic questioning as well as spontaneous self-report. As part of the informed consent procedure, patients received an information letter stating possible side effects of topiramate. Lean body mass was assessed by bioelectrical impedance analysis (Bodystat 1500, Bodystat Ltd., Douglas, Isle of Man, UK). On the last 3 days of both intervention periods, subjects were asked to register their food intake in a diary.

\section{Clamp studies}

At the end of each 4-week intervention period, a hyperglycemic clamp (day 27) and a hyperinsulinemic euglycemic clamp (day 28) were performed.

Hyperglycemic clamp $\beta$-Cell function in response to glucose was assessed using the hyperglycemic clamp. $\beta$-Cell insulin production can be divided into an early phase (0-10 min) and a late phase (80-120 min). After an overnight fast, a priming dose of $20 \%$ glucose of $9.6 \mathrm{mg} / \mathrm{m}^{2}$ was infused in the first $14 \mathrm{~min}$ to raise the plasma glucose concentration by $7 \mathrm{mmol} / \mathrm{l}$. Hereafter, a maintenance dose of $20 \%$ glucose was infused and the infusion rate was adjusted at 5-min intervals to maintain the plasma glucose level. Blood samples for determining insulin production during the early phase were drawn at $0,2,4,6,8$, and $10 \mathrm{~min}$ and at $80,90,100,110$, and $120 \mathrm{~min}$ for the late phase.

The glucose-dependent insulin response (IR), a measure of the $\beta$-cell function, was calculated as the increase in insulin from baseline $(\mathrm{pmol} / \mathrm{l})$ divided by the increase in glucose from baseline ( $\mathrm{mmol} / \mathrm{l})$. In addition, the area under the curve (AUC) for insulin was calculated for both the early and the late phase insulin release $(13,14)$.

Hyperinsulinemic euglycemic clamp Both hepatic and peripheral insulin sensitivities were measured using the hyperinsulinemic euglycemic clamp, as described previously (15). In short, after an overnight fast, samples were taken for the measurement of basal levels of glucose, insulin, and background enrichment of $\left[6,6-{ }^{2} \mathrm{H}_{2}\right]$-glucose. After $2 \mathrm{~h}$ of continuous infusion of $\left[6,6-{ }^{2} \mathrm{H}_{2}\right]$-glucose (Cambridge Isotopes, Cambridge, MA, USA), basal rates of glucose turnover were assessed. To attain a more accurate estimate of hepatic insulin sensitivity, a two-step hyperinsulinemic euglycemic clamp was performed using a low $\left(10 \mathrm{mU} / \mathrm{m}^{2}\right.$ per $\mathrm{min})$ and a high $\left(40 \mathrm{mU} / \mathrm{m}^{2}\right.$ per $\left.\mathrm{min}\right)$ insulin infusion rate for $2 \mathrm{~h}$ each (Actrapid, Novo Nordisk Pharma, Alphen aan de Rijn, The Netherlands). Infusion of a variable rate of $20 \%$ glucose enriched with $3 \%$ $\left[6,6-{ }^{2} \mathrm{H}_{2}\right]$-glucose was used to maintain glucose values at $5.0 \mathrm{mmol} / \mathrm{l}$. In the last $30 \mathrm{~min}$ of each $2-\mathrm{h}$ step, blood samples were taken every $10 \mathrm{~min}$ to estimate glucose disposal rate and endogenous glucose production (EGP) $(16,17)$.

The rates of appearance $\left(R_{\mathrm{a}}\right)$ and disappearance $\left(R_{\mathrm{d}}\right)$ for glucose were calculated as the tracer infusion rate divided by the tracer-to-trace ratio. The EGP during the two clamp steps was calculated as the difference between the rates of glucose appearance and glucose infusion (18).

\section{Indirect calorimetry}

Indirect calorimetry with a ventilated hood (Oxycon Beta, Mijnhardt Jaegher, Breda, The Netherlands) was performed for 30 min under basal conditions and during the second step of the hyperinsulinemic euglycemic clamp to estimate energy expenditure and substrate oxidation rates. Total glucose and lipid oxidation rates were calculated as described previously (19). Nonoxidative glucose disposal (NOGD), as a measurement for glycogen storage, was calculated by subtracting the glucose oxidation rate from the $R_{\mathrm{d}}$ of glucose. 


\section{Assays}

Serum insulin was measured with an IRMA (Biosource, Nivelles, Belgium). HbA1c was measured with a semiautomated HPLC machine Primus Ultra 2 (Kordia, Leiden, The Netherlands). Serum glucose and $\left[6,6-{ }^{2} \mathrm{H}_{2}\right]$-glucose were measured in a single analytical run, using gas chromatography coupled to mass spectrometry as described previously $(20,21)$.

\section{Statistical analysis}

The primary end point of our study was insulin sensitivity measured as the glucose disposal rate during a hyperinsulinemic euglycemic clamp with stable isotopes. As data on glucose disposal rates for our specific population were not available at the time of protocol writing, sample size was calculated using data on insulin sensitivity as measured by the $M$-value (i.e. whole-body glucose uptake measured as the glucose infusion rate required to maintain euglycemia during a hyperinsulinemic euglycemic clamp) obtained in 22 nonsmoking obese female patients (22). We estimated that a sample size of ten subjects would provide $80 \%$ power to detect a $15 \%$ difference in the primary end point between the two interventions at a two-sided significance level of 0.05 according to the Altman's nomogram for sample size calculations (23). Taking into account the possibility of dropouts, we wanted to include at least 13 patients in our study.

Results are expressed as mean \pm s.E.M. The paired Student's $t$-test was used for comparisons within patients between the two interventions. A nonparametric test (Wilcoxon signed-rank test for paired samples) was applied when appropriate. A $P$ value of $<0.05$ was considered statistically significant. No adjustment for a potential carryover effect was planned (24). Statistical analyses were performed using SPSS for Windows (release 18.0, SPSS, Inc., Chicago, IL, USA).

\section{Results}

\section{Subjects}

A total of 145 subjects were screened for eligibility and 15 subjects met inclusion criteria. Two subjects withdrew informed consent before the start of the study; therefore, 13 subjects were randomized. All subjects completed both intervention periods and there were no dropouts from the study. Subjects were insulin resistant (HOMA-IR 2.0 \pm 0.2 ) and obese with an average BMI of $36.6 \pm 1.3 \mathrm{~kg} / \mathrm{m}^{2}$ (except for one subject with a BMI of $29.0 \mathrm{~kg} / \mathrm{m}^{2}$ ). Other baseline characteristics are shown in Table 1 .

Patient characteristics (weight, BMI, and waist circumference) and laboratory values (lipid levels, insulin, and glucose) were similar at the start of study period 1 and the start of study period 2 . This is in
Table 1 Anthropometric and laboratory parameters before and after 4 weeks of treatment with topiramate vs placebo in obese, insulin-resistant women. Mean \pm S.E.M.

\begin{tabular}{|c|c|c|c|c|}
\hline & \multicolumn{2}{|c|}{ Placebo } & \multicolumn{2}{|c|}{ Topiramate } \\
\hline & Before & After & Before & After \\
\hline Age (years) & $44.6 \pm 3.3$ & & & \\
\hline Height $(\mathrm{cm})$ & $1.69 \pm 0.01$ & & & \\
\hline Weight (kg) & $104.2 \pm 4.6$ & $104.1 \pm 4.6$ & $104.3 \pm 4.7$ & $103.3 \pm 4.6^{\star, \dagger}$ \\
\hline Waist (cm) & $108 \pm 3.5$ & $109 \pm 3.3$ & $108 \pm 3.3$ & $108 \pm 3.2$ \\
\hline Fat mass $(\mathrm{kg})$ & $49.1 \pm 3.3$ & $48.6 \pm 3.3$ & $49.1 \pm 3.4$ & $48.4 \pm 3.3$ \\
\hline $\begin{array}{l}\text { Systolic BP } \\
(\mathrm{mmHg})\end{array}$ & $144 \pm 4.4$ & $146 \pm 5.1$ & $143 \pm 4.9$ & $143 \pm 4.3$ \\
\hline $\begin{array}{l}\text { Diastolic BP } \\
(\mathrm{mmHg})\end{array}$ & $90 \pm 3.2$ & $89 \pm 2.8$ & $88 \pm 2.9$ & $87 \pm 2.4$ \\
\hline $\begin{array}{l}\text { Fasting glucose } \\
\quad(\mathrm{mmol} / \mathrm{l})\end{array}$ & $5.2 \pm 0.2$ & $5.2 \pm 0.1$ & $5.2 \pm 0.2$ & $5.3 \pm 0.2$ \\
\hline $\begin{array}{l}\text { Fasting insulin } \\
(\mathrm{pmol} / \mathrm{l})\end{array}$ & $106.3 \pm 10.9$ & $102.6 \pm 9.8$ & $106.8 \pm 9.1$ & $100.4 \pm 9.9$ \\
\hline HOMA-IR & $2.0 \pm 0.2$ & $2.0 \pm 0.2$ & $2.0 \pm 0.2$ & $1.8 \pm 0.2$ \\
\hline
\end{tabular}

${ }^{\star} P<0.05$ topiramate vs placebo; ${ }^{\dagger} P<0.01$ before vs after. BP, blood pressure; HOMA-IR, homeostasis model of assessment-insulin resistance.

accordance with the assumption of no carryover effect or period effect.

\section{Anthropometric and laboratory measurements}

Body weight was significantly lower after the topiramate period (T: $104.1 \pm 4.6$ vs $\mathrm{P}: 103.3 \pm 4.6 \mathrm{~kg}$, $P<0.05)$. No significant differences in fat mass and blood pressure were observed after topiramate treatment. Topiramate did not affect plasma glucose concentration in the fasting condition (T: $5.3 \pm 0.2 \mathrm{mmol} / \mathrm{l}$ vs $\mathrm{P}: 5.2 \pm 0.1 \mathrm{mmol} / \mathrm{l} ; P=\mathrm{NS}$, Table 1). Average food intake during the last 3 days did not differ between the two intervention periods (T: $1831 \pm 81 \mathrm{kcal} /$ day vs $\mathrm{P}: 1743 \pm 98 \mathrm{kcal} /$ day; $P=\mathrm{NS}$ ).

\section{Insulin sensitivity}

Plasma glucose levels in both steps of the hyperinsulinemic euglycemic clamp were similar between the two interventions (step 1, T: $5.0 \pm 0.1 \mathrm{mmol} / \mathrm{l}$ vs P: $5.0 \pm 0.1 \mathrm{mmol} / \mathrm{l}$; step 2 , T: $4.9 \pm 0.1 \mathrm{mmol} / \mathrm{l}$ vs $\mathrm{P}: 4.7 \pm 0.1 \mathrm{mmol} / \mathrm{l} ; \quad P=\mathrm{NS})$. Insulin levels were comparable as well (step 1, T: $121.1 \pm 9.0 \mathrm{pmol} / \mathrm{l} \mathrm{vs}$ $\mathrm{P}: 128.3 \pm 9.7 \mathrm{pmol} / \mathrm{l}$; step 2 , T: $305.8 \pm 15.0 \mathrm{pmol} / \mathrm{l}$ vs $P$ : $323.6 \pm 20.2 \mathrm{pmol} / \mathrm{l} ; P=\mathrm{NS}$ ).

Peripheral insulin sensitivity was not affected by topiramate; the insulin-stimulated $R_{\mathrm{d}}$ of glucose did not significantly differ during both steps of the hyperinsulinemic euglycemic clamp after the two interventions (Fig. 1). In addition, there was no difference in EGP between the two treatments (step 1, T: $13.2 \pm 0.7 \mu \mathrm{mol} / \mathrm{kg}_{\mathrm{LBM}}$ per min vs P: $13.2 \pm 0.9 \mu \mathrm{mol} / \mathrm{kg}_{\mathrm{LBM}}$ per $\mathrm{min}$; step 2 , $\mathrm{T}: 5.1 \pm 0.5 \mu \mathrm{mol} / \mathrm{kg}_{\mathrm{LBM}}$ per min vs P: $4.7 \pm 0.5 \mu \mathrm{mol} / \mathrm{kg}_{\mathrm{LBM}}$ per min; $P=$ NS, Table 2 ). 

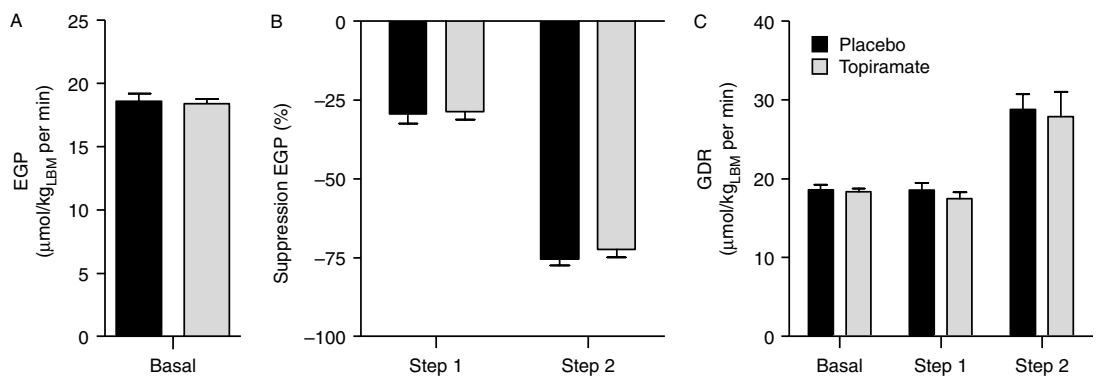

Figure 1 (A) Basal endogenous glucose production (EGP) during the hyperinsulinemic euglycemic clamp after treatment with topiramate vs placebo. (B) Suppression of EGP during the two-step hyperinsulinemic euglycemic clamp after treatment with topiramate vs placebo. (C) Insulin-stimulated glucose disposal rate (GDR) during the two-step hyperinsulinemic euglycemic clamp after treatment with topiramate vs placebo.

\section{Insulin secretion}

Average clamp glucose levels during the early phase of the hyperglycemic clamp were similar between interventions. During the late phase, the glucose level was slightly higher in topiramate-treated subjects (T: $12.0 \pm$ $0.2 \mathrm{mmol} / \mathrm{l}$ vs $\mathrm{P}: 11.6 \pm 0.3 \mathrm{mmol} / \mathrm{l} ; P<0.05)$.

Insulin levels were similar in placebo- and topiramate-treated subjects throughout the $120 \mathrm{~min}$ of the hyperglycemic clamp. The AUC of insulin in the early $(0-10 \mathrm{~min})$ and late $(80-120 \mathrm{~min})$ phase was not different after topiramate treatment. Furthermore, the IRs in both the early (T: $35.5 \pm 14.5 \mathrm{pmol} / \mathrm{l} \times \mathrm{mmol} / \mathrm{l}^{-1}$ vs $\left.\mathrm{P}: 28.1 \pm 6.4 \mathrm{pmol} / \mathrm{l} \times \mathrm{mmol} / \mathrm{l}^{-1} ; P=\mathrm{NS}\right)$ and the late (T: $107.4 \pm 18.5$ vs P: $104.6 \pm 23.5 \mathrm{pmol} / \mathrm{l} \times$ $\mathrm{mmol} / \mathrm{l}^{-1} ; P=\mathrm{NS}$ ) phases were not different (Fig. 2).

\section{Indirect calorimetry}

Both under basal and hyperinsulinemic conditions, there were no differences in glucose and lipid oxidation rates between the two interventions. Resting energy expenditure and NGOD did not differ either (Table 2).

\section{Adverse events}

The use of topiramate was associated with considerable side effects, as shown in Table 3. The most common adverse events were related to the nervous system, with paresthesia being the most reported side effect. None of the subjects withdrew because of side effects and no serious adverse events occurred. There were no statistically significant changes in laboratory values, except a

Table 2 Metabolic parameters after 4 weeks of treatment with topiramate vs placebo in obese, insulin-resistant women. Mean \pm S.E.M.

\begin{tabular}{|c|c|c|}
\hline & Placebo & Topiramate \\
\hline \multicolumn{3}{|l|}{ Hyperglycemic clamp } \\
\hline \multicolumn{3}{|l|}{ First phase } \\
\hline Average glucose (mmol/l) & $8.8 \pm 0.3$ & $8.5 \pm 0.3$ \\
\hline Average insulin (pmol/l) & $1335.6 \pm 177.4$ & $1401.4 \pm 227.1$ \\
\hline Insulin increase above baseline (pmol/l) & $743.5 \pm 186.7$ & $662.5 \pm 164.8$ \\
\hline AUC insulin (pmol/l) & $1929.6 \pm 265.7$ & $2024.7 \pm 333.6$ \\
\hline Insulin response $\left(\mathrm{pmol} / \mathrm{l} \times \mathrm{mmol} / \mathrm{I}^{-1}\right)$ & $28.1 \pm 6.4$ & $35.5 \pm 14.5$ \\
\hline \multicolumn{3}{|l|}{ Second phase } \\
\hline Average glucose $(\mathrm{mmol} / \mathrm{l})$ & $11.6 \pm 0.3$ & $12.0 \pm 0.2^{*}$ \\
\hline Average insulin (pmol/l) & $4902.0 \pm 887.7$ & $5480.8 \pm 920.1$ \\
\hline Insulin increase above baseline (pmol/l) & $4185.87 \pm 860.9$ & $4631.1 \pm 873.2$ \\
\hline AUC insulin (pmol/l) & $28017.7 \pm 5029.9$ & $31567.7 \pm 5376.2$ \\
\hline Insulin response $\left(\mathrm{pmol} / \mathrm{I} \times \mathrm{mmol} / \mathrm{I}^{-1}\right)$ & $104.6 \pm 23.5$ & $107.4 \pm 18.5$ \\
\hline \multicolumn{3}{|l|}{ Hyperinsulinemic euglycemic clamp } \\
\hline Basal EGP ( $\mu \mathrm{mol} / \mathrm{kg}_{\mathrm{LBM}}$ per min) & $18.6 \pm 0.6$ & $18.4 \pm 0.4$ \\
\hline Clamp step $1 M$-value ( $\mu \mathrm{mol} / \mathrm{kg}_{\text {LBM }}$ per $\min$ ) & $4.2 \pm 1.1$ & $11.2 \pm 4.9$ \\
\hline Clamp step $2 M$-value ( $\mu \mathrm{mol} / \mathrm{kg}_{\text {LBM }}$ per min) & $23.4 \pm 2.2$ & $25.6 \pm 3.2$ \\
\hline Clamp step 1 EGP $\left(\mu \mathrm{mol} / \mathrm{kg}_{\mathrm{LBM}}\right.$ per $\left.\mathrm{min}\right)$ & $13.2 \pm 0.9$ & $13.2 \pm 0.7$ \\
\hline Clamp step 2 EGP ( $\mu \mathrm{mol} / \mathrm{kg}_{\text {LBM }}$ per min) & $4.7 \pm 0.5$ & $5.1 \pm 0.5$ \\
\hline Clamp step $1 R_{\mathrm{d}}\left(\mu \mathrm{mol} / \mathrm{kg}_{\mathrm{LBM}}\right.$ per $\left.\mathrm{min}\right)$ & $18.5 \pm 1.0$ & $17.5 \pm 0.8$ \\
\hline Clamp step $2 R_{\mathrm{d}}\left(\mu \mathrm{mol} / \mathrm{kg}_{\mathrm{LBM}}\right.$ per min) & $28.8 \pm 1.9$ & $27.9 \pm 3.2$ \\
\hline \multicolumn{3}{|l|}{ Indirect calorimetry } \\
\hline Resting energy expenditure (kcal) & $1770 \pm 77$ & $1804 \pm 63$ \\
\hline Basal glucose ox ( $\mu \mathrm{mol} / \mathrm{kg}_{\mathrm{LBM}}$ per min) & $10.9 \pm 1.3$ & $9.7 \pm 2.0$ \\
\hline Clamp glucose ox ( $\mu \mathrm{mol} / \mathrm{kg}_{\text {LBM }}$ per min $)$ & $18.7 \pm 1.3$ & $19.4 \pm 1.2$ \\
\hline Basal NOGD ( $\mu \mathrm{mol} / \mathrm{kg}_{\mathrm{LBM}}$ per min) & $7.8 \pm 1.4$ & $8.7 \pm 1.9$ \\
\hline Clamp NOGD ( $\mu \mathrm{mol} / \mathrm{kg}_{\mathrm{LBM}}$ per min) & $10.9 \pm 2.1$ & $8.5 \pm 2.7$ \\
\hline Basal lipid ox ( $\mu \mathrm{mol} / \mathrm{kg}_{\text {LBM }}$ per $\left.\min \right)$ & $5.4 \pm 0.5$ & $5.9 \pm 0.4$ \\
\hline Clamp lipid ox ( $\mu \mathrm{mol} / \mathrm{kg}_{\mathrm{LBM}}$ per min) & $3.0 \pm 0.4$ & $2.9 \pm 0.3$ \\
\hline
\end{tabular}

${ }^{\star} P<0.05$. AUC, area under the curve; LBM, lean body mass; EGP, endogenous glucose production; $R_{\mathrm{d}}$, rate of disappearance for glucose; ox, oxidation; NOGD, nonoxidative glucose disposal. 

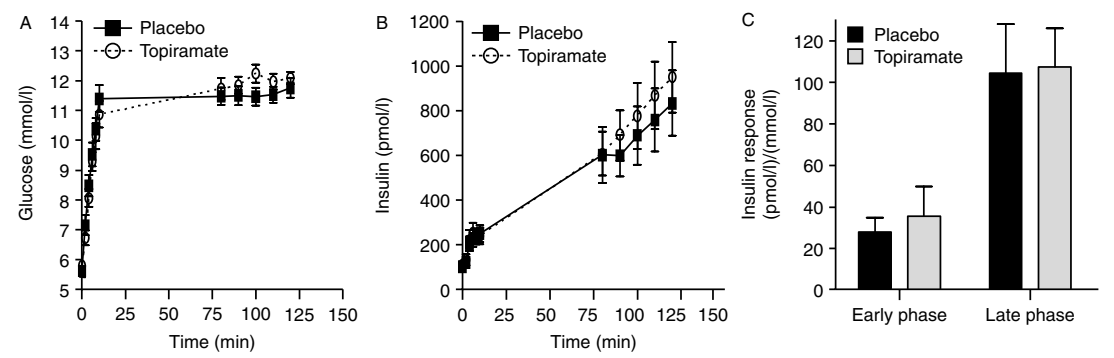

Figure 2 (A) Glucose levels during the hyperglycemic clamp after treatment with topiramate vs placebo. (B) Insulin levels during the hyperglycemic clamp after treatment with topiramate vs placebo. (C) Insulin response in the early and late phase of the hyperglycemic clamp after treatment with topiramate vs placebo. slight decrease in bicarbonate (T: $18 \pm 1 \mathrm{mmol} / \mathrm{l}$ vs $\mathrm{P}$ : $22 \pm 1 \mathrm{mmol} / \mathrm{l} ; P \leq 0.001)$ and increase in chloride (T: $110 \pm 1 \mathrm{mmol} / \mathrm{l}$ vs $\mathrm{P}: 107 \pm 1 \mathrm{mmol} / \mathrm{l} ; P \leq 0.001$ ), which was expected because of the known carbonic anhydrase inhibitory effect of topiramate. No clinically manifest metabolic acidosis occurred.

\section{Discussion}

This study shows that short-term, low-dose topiramate treatment ( 4 weeks, $75 \mathrm{mg} /$ day) does not affect insulin sensitivity and insulin secretion in obese, insulinresistant women and causes typical, bothersome side effects. Despite the low-dose, short-term treatment, subjects did lose a small but statistically significant amount of weight. However, we could not find any effect of topiramate treatment on EGP and glucose disposal, as evaluated by a two-step hyperinsulinemic euglycemic clamp.

In animal studies, topiramate has been shown to have an insulin-sensitizing effect $(6,8)$; however, whether this is the case in humans is currently still under debate. Studies in obese subjects have shown that long-term topiramate treatment (24-60 weeks, 64-384 mg/day) leads to significant weight loss $(2,3,4)$ and reduces glucose levels in obese patients with epilepsy $(25,26,27)$. Furthermore, topiramate treatment (16-40 weeks, 96-192 mg/day) causes a significant decrease in HbA1c in T2DM patients $(9,10,11)$. These studies also showed that topiramate improves the 2-h plasma glucose level in response to an $\operatorname{OGTT}(9,10)$, suggesting that it ameliorates glucose tolerance. However, these results were achieved in patients who lost a significant amount of weight $(-6.0$ and $-9.1 \mathrm{~kg})$; therefore, it is not known whether these effects on glycemic control parameters are independent of the weight loss effect of topiramate. In addition, $\mathrm{Li}$ et al. (28) observed no differences in HOMA-IR after 6 months of topiramate treatment in children with epilepsy (median dosage $2.15 \mathrm{mg} / \mathrm{kg} /$ day). In a study of Eliasson et al. (29) in T2DM patients, an improvement in insulin-stimulated glucose disposal (using a hyperinsulinemic euglycemic clamp) could not be detected after 11 months of topiramate treatment (192 mg/day), despite a significant decrease in body weight, fasting plasma glucose, and HbA1c. A trend in enhanced hepatic insulin sensitivity was observed, but this difference did not reach statistical significance, perhaps because of the limited sample size and the relatively high-insulin infusion rate $(1 \mathrm{mU} / \mathrm{kg}$ per $\mathrm{min})$, which might be expected to suppress hepatic glucose production almost completely. The authors suggested that the effects of topiramate on fasting plasma glucose and $\mathrm{HbA} 1 \mathrm{c}$ could be due to a nondetectable improvement in hepatic insulin sensitivity or an improvement in $\beta$-cell function. In this study, we used a two-step clamp to get a more accurate estimate of hepatic insulin sensitivity $(16,17)$. However, no difference in hepatic insulin sensitivity could be detected.

Even using very accurate methods, we thus could not find an effect of topiramate on insulin sensitivity. This can possibly be explained by the fact that a 4-week treatment period with an escalating dose could be insufficient to show a drug effect. Also, we used a low dose of topiramate, although our dose was high enough to cause some weight loss. Furthermore, Bray et al. (3) showed significant effects of $64 \mathrm{mg}$ topiramate per day on weight and $\mathrm{HbA1c}$ comparable to the effect of a dose of $96 \mathrm{mg} /$ day, albeit over a period of 24 weeks. Moreover, our dosage resulted in significant side effects known to be caused by topiramate treatment and it led to a significant, but clinically irrelevant, change in plasma bicarbonate and chloride levels.

To assess $\beta$-cell function, we performed a hyperglycemic clamp. Animal studies have shown that topiramate can improve obesity-associated $\beta$-cell

Table 3 Adverse events during treatment with topiramate vs placebo in obese, insulin-resistant women.

\begin{tabular}{lcc}
\hline & \multicolumn{2}{c}{ Number of subjects with event $(n)$} \\
\cline { 2 - 3 } Adverse event & Placebo $(n=13)$ & Topiramate $(n=13)$ \\
\hline Fatigue & 1 & 4 \\
Headache & 7 & 3 \\
Dizziness & 4 & 5 \\
Sleepiness & 1 & 1 \\
Concentration & 1 & 5 \\
$\quad$ problems & & \\
Nausea & 1 & 6 \\
Paresthesia & 2 & 8 \\
Emotional/irritation & 0 & 2 \\
Constipation & 2 & 4 \\
\hline
\end{tabular}


dysfunction (5). In addition, Frigerio et al. (30) demonstrated that topiramate partially reversed the lipotoxic effect on $\beta$-cells, resulting in enhanced insulin secretion. As far as we know, our study is the first human study to formally evaluate the effect of topiramate on $\beta$-cell function by a hyperglycemic clamp. A significant impact on glucose-induced insulin release could not be shown, although there was a trend for an increased second-phase AUC of insulin in the topiramate group. However, during this phase, the average serum glucose was significantly higher in the topiramate treatment arm and the IR, which is corrected for the difference in glucose levels, and is similar between the two groups. On the other hand, it cannot be completely excluded that with the study of additional participants, a significant difference will be shown, as we did not power our study on insulin secretion.

Strengths of our study are the randomized, placebocontrolled design, the use of standard assessments for investigating insulin sensitivity, as well as insulin secretion and retention of all study participants. A crossover design has advantages, such as the elimination of between-subject variability. There are also some limitations, for example, the risk of a carryover or a period effect and a risk of subjects dropping out after the first period (31). Crossover studies can therefore only be used with interventions that have no permanent effect on the outcome parameter and for conditions that do not change spontaneously over time. A carryover effect was not expected because of the washout period and because of the temporary effect of topiramate on insulin sensitivity in the absence of significant weight loss. As clamp studies are costly and time consuming for subjects as well as research staff, it was not feasible to obtain data on insulin sensitivity and secretion at the start of both treatment periods. However, subjects were comparable with respect to other variables, such as fasting glucose and HOMA-IR before the start of both treatment arms. A period effect was also not expected as insulin sensitivity is not expected to change spontaneously over a period of 12 weeks. Also, patient characteristics (weight, BMI, and waist circumference) and laboratory values (lipid levels, insulin, and glucose) were similar at the start of study period 1 and the start of study period 2 .

Another limitation of our study is that although the aim of our study was to assess the effect of topiramate treatment independent of weight loss, subjects nonetheless did lose weight during the topiramate treatment period, albeit a small amount. It is currently not fully known how topiramate exerts its effect on body weight, but several mechanisms have been proposed (32). For example, studies have shown that topiramate decreases food intake in animals as well as in humans $(8,33)$. Furthermore, animal studies showed that topiramate treatment can increase energy expenditure and decrease energetic efficiency $(34,35)$. This, however, was not demonstrated in humans (33). Why topiramate causes weight reduction in some patients but not in others is also up for debate. It seems that topiramateinduced weight loss is correlated with baseline BMI, causing a greater amount of weight loss in obese patients. Data on the effect of drug dosage and gender are, however, conflicting $(26,32)$. As there was no difference in food intake or energy expenditure between the two interventions in our study, it remains unclear what has caused the decrease in body weight. However, as these were not primary outcome measurements, our study was not powered to detect a difference in food intake or energy expenditure. Another explanation for the weight loss could be an increase in physical activity. Unfortunately, this was not measured in our study.

In conclusion, this study shows that low-dose topiramate treatment for 4 weeks did not have a significant effect on insulin sensitivity or $\beta$-cell function in 13 adult females without diabetes and in addition causes bothersome side effects.

\section{Declaration of interest}

M A Sleddering, M Snel, T C M Streefland, and I M Jazet have nothing to disclose. H Pijl received a research grant from Top Institute Pharma for the execution of this study.

\section{Funding}

This study was financially supported by Top Institute Pharma, grant no T2-105.

\section{Author contribution statement}

M A Sleddering contributed to data collection and analysis, data interpretation, and manuscript writing. M Snel contributed to design and conduct of the study, data collection and analysis, data interpretation, and manuscript writing. T C M Streefland contributed to data collection and analysis. I M Jazet contributed to design and conduct of the study, data interpretation, and manuscript writing. $\mathrm{H}$ Pijl contributed to design and conduct of the study, data interpretation, and manuscript writing.

\section{References}

1 Astrup A \& Toubro S. Topiramate: a new potential pharmacological treatment for obesity. Obesity Research 200412 (Suppl) 167S-173S. (doi:10.1038/oby.2004.284)

2 Astrup A, Caterson I, Zelissen P, Guy-Grand B, Carruba M, Levy B, Sun X \& Fitchet M. Topiramate: long-term maintenance of weight loss induced by a low-calorie diet in obese subjects. Obesity Research 200412 1658-1669. (doi:10.1038/oby.2004.206)

3 Bray GA, Hollander P, Klein S, Kushner R, Levy B, Fitchet M \& Perry BH. A 6-month randomized, placebo-controlled, doseranging trial of topiramate for weight loss in obesity. Obesity Research 200311 722-733. (doi:10.1038/oby.2003.102)

4 Wilding J, Van Gaal L, Rissanen A, Vercruysse F \& Fitchet M. A randomized double-blind placebo-controlled study of the longterm efficacy and safety of topiramate in the treatment of obese subjects. International Journal of Obesity and Related Metabolic Disorders 200428 1399-1410. (doi:10.1038/sj.ijo.0802783)

5 Liang Y, Chen X, Osborne M, DeCarlo SO, Jetton TL \& Demarest K. Topiramate ameliorates hyperglycaemia and improves glucose- 
stimulated insulin release in ZDF rats and $\mathrm{db} / \mathrm{db}$ mice. Diabetes, Obesity \& Metabolism 20057 360-369. (doi:10.1111/j.14631326.2004.00403.x)

6 Liang Y, She P, Wang X \& Demarest K. The messenger RNA profiles in liver, hypothalamus, white adipose tissue, and skeletal muscle of female Zucker diabetic fatty rats after topiramate treatment. Metabolism 200655 1411-1419. (doi:10.1016/j.metabol.2006. 06.013)

7 Wilkes JJ, Nguyen MT, Bandyopadhyay GK, Nelson E \& Olefsky JM. Topiramate treatment causes skeletal muscle insulin sensitization and increased Acrp30 secretion in high-fat-fed male Wistar rats. American Journal of Physiology. Endocrinology and Metabolism 2005 289 E1015-E1022. (doi:10.1152/ajpendo.00169.2005)

8 Wilkes JJ, Nelson E, Osborne M, Demarest KT \& Olefsky JM. Topiramate is an insulin-sensitizing compound in vivo with direct effects on adipocytes in female ZDF rats. American Journal of Physiology. Endocrinology and Metabolism 2005288 E617-E624. (doi:10.1152/ajpendo.00437.2004)

9 Rosenstock J, Hollander P, Gadde KM, Sun X, Strauss R \& Leung A. A randomized, double-blind, placebo-controlled, multicenter study to assess the efficacy and safety of topiramate controlled release in the treatment of obese type 2 diabetic patients. Diabetes Care 2007 30 1480-1486. (doi:10.2337/dc06-2001)

10 Stenlof K, Rossner S, Vercruysse F, Kumar A, Fitchet M \& Sjostrom L. Topiramate in the treatment of obese subjects with drug-naive type 2 diabetes. Diabetes, Obesity \& Metabolism 20079 360-368. (doi:10.1111/j.1463-1326.2006.00618.x)

11 Toplak H, Hamann A, Moore R, Masson E, Gorska M, Vercruysse F, Sun X \& Fitchet M. Efficacy and safety of topiramate in combination with metformin in the treatment of obese subjects with type 2 diabetes: a randomized, double-blind, placebocontrolled study. International Journal of Obesity $2007 \mathbf{3 1}$ 138-146. (doi:10.1038/sj.ijo.0803382)

12 World Medical Association. Declaration of Helsinki: Ethical Principles for Medical Research Involving Human Subjects. Adopted by the 18th WMA General Assembly, Helsinki, Finland, June 1964 , and amended by the $59^{\text {th }}$ WMA General Assembly, Seoul, Korea, October 2008.

13 DeFronzo RA, Tobin JD \& Andres R. Glucose clamp technique: a method for quantifying insulin secretion and resistance. American Journal of Physiology 1979237 E214-E223.

14 Kashyap S, Belfort R, Gastaldelli A, Pratipanawatr T, Berria R, Pratipanawatr W, Bajaj M, Mandarino L, DeFronzo R \& Cusi K. A sustained increase in plasma free fatty acids impairs insulin secretion in nondiabetic subjects genetically predisposed to develop type 2 diabetes. Diabetes 200352 2461-2474. (doi:10.2337/diabetes.52.10.2461)

15 Jazet IM, Pijl H, Frolich M, Romijn JA \& Meinders AE. Two days of a very low calorie diet reduces endogenous glucose production in obese type 2 diabetic patients despite the withdrawal of blood glucose-lowering therapies including insulin. Metabolism 200554 705-712. (doi:10.1016/j.metabol.2004.12.015)

16 Gastaldelli A, Miyazaki Y, Pettiti M, Santini E, Ciociaro D, DeFronzo RA \& Ferrannini E. The effect of rosiglitazone on the liver: decreased gluconeogenesis in patients with type 2 diabetes. Journal of Clinical Endocrinology and Metabolism 200691 806-812. (doi:10.1210/jc.2005-1159)

17 Klein S, Fontana L, Young VL, Coggan AR, Kilo C, Patterson BW \& Mohammed BS. Absence of an effect of liposuction on insulin action and risk factors for coronary heart disease. New England Journal of Medicine $2004 \quad 350 \quad 2549-2557$. (doi:10.1056/ NEJMoa033179)

18 Steele R. Influences of glucose loading and of injected insulin on hepatic glucose output. Annals of the New York Academy of Sciences 1959 82 420-430. (doi:10.1111/j.1749-6632.1959.tb44923.x)

19 Simonson DC \& DeFronzo RA. Indirect calorimetry: methodological and interpretative problems. American Journal of Physiology 1990258 E399-E412.
20 Ackermans MT, Ruiter AF \& Endert E. Determination of glycerol concentrations and glycerol isotopic enrichments in human plasma by gas chromatography/mass spectrometry. Analytical Biochemistry 1998258 80-86. (doi:10.1006/abio.1997.2535)

21 Reinauer H, Gries FA, Hubinger A, Knode O, Severing K \& Susanto F. Determination of glucose turnover and glucose oxidation rates in man with stable isotope tracers. Journal of Clinical Chemistry and Clinical Biochemistry 199028 505-511.

22 Karelis AD, Faraj M, Bastard JP, St Pierre DH, Brochu M, Prud'homme D \& Rabasa-Lhoret R. The metabolically healthy but obese individual presents a favorable inflammation profile. Journal of Clinical Endocrinology and Metabolism 200590 4145-4150. (doi:10.1210/jc.2005-0482)

23 Altman DG. Statistics and ethics in medical research: III How large a sample? BMJ 1980281 1336-1338. (doi:10.1136/bmj.281. 6251.1336)

24 Senn S, D'Angelo G \& Potvin D. Carry-over in cross-over trials in bioequivalence: theoretical concerns and empirical evidence. Pharmaceutical Statistics 20043 133-142. (doi:10.1002/pst.111)

25 Asconapé JJ. Some common issues in the use of antiepileptic drugs. Seminars in Neurology 200222 027-040. (doi:10.1055/s-200233046)

26 Ben-Menachem E, Axelsen M, Johanson EH, Stagge A \& Smith U. Predictors of weight loss in adults with topiramate-treated epilepsy. Obesity Research 200311 556-562. (doi:10.1038/oby. 2003.78)

27 Biton V. Effect of antiepileptic drugs on bodyweight: overview and clinical implications for the treatment of epilepsy. CNS Drugs 2003 17 781-791. (doi:10.2165/00023210-200317110-00002)

28 Li HF, Zou Y, Xia ZZ, Gao F, Feng JH \& Yang CW. Effects of topiramate on weight and metabolism in children with epilepsy. Acta Paediatrica 200998 1521-1525. (doi:10.1111/j.16512227.2009.01349.x)

29 Eliasson B, Gudbjornsdottir S, Cederholm J, Liang Y, Vercruysse F \& Smith U. Weight loss and metabolic effects of topiramate in overweight and obese type 2 diabetic patients: randomized doubleblind placebo-controlled trial. International Journal of Obesity 2007 31 1140-1147. (doi:10.1038/sj.ijo.0803548)

30 Frigerio F, Chaffard G, Berwaer M \& Maechler P. The antiepileptic drug topiramate preserves metabolism-secretion coupling in insulin secreting cells chronically exposed to the fatty acid oleate. Biochemical Pharmacology 200672 965-973. (doi:10.1016/j.bcp. 2006.07.013)

31 Mills EJ, Chan AW, Wu P, Vail A, Guyatt GH \& Altman DG. Design, analysis, and presentation of crossover trials. Trials 20091027. (doi:10.1186/1745-6215-10-27)

32 Verrotti A, Scaparrotta A, Agostinelli S, Di PS, Chiarelli F \& Grosso S. Topiramate-induced weight loss: a review. Epilepsy Research 201195 189-199. (doi:10.1016/j.eplepsyres.2011.05.014)

33 Tremblay A, Chaput JP, Berube-Parent S, Prud'homme D, Leblanc C, Almeras N \& Despres JP. The effect of topiramate on energy balance in obese men: a 6-month double-blind randomized placebo-controlled study with a 6-month open-label extension. European Journal of Clinical Pharmacology 200763 123-134. (doi:10.1007/s00228-006-0220-1)

34 Picard F, Deshaies Y, Lalonde J, Samson P \& Richard D. Topiramate reduces energy and fat gains in lean $(\mathrm{Fa} /$ ? $)$ and obese (fa/fa) Zucker rats. Obesity Research 20008 656-663. (doi:10.1038/oby.2000.84)

35 Richard D, Ferland J, Lalonde J, Samson P \& Deshaies Y. Influence of topiramate in the regulation of energy balance. Nutrition 2000 16 961-966. (doi:10.1016/S0899-9007(00)00452-4)

Received 8 June 2012

Revised version received 28 August 2012

Accepted 14 September 2012 